\title{
RELATIONS ARISING FROM UNJUST ENRICHMENT AND THEIR CLASSIFICATION
}

\author{
Daria A. Peregudova \\ Volgograd Academy of the Ministry of Internal Affairs of the Russian Federation, Volgograd, Russian Federation
}

Introduction: the paper deals with the topical issues related to the obligations due to unjust enrichment. In the civil legislation, there is only one classification, which contains two types of enrichment by the method of origin: as a result of unjust acquisition of property and as a result of unjust saving of property. In this regard, the paper considers the types of enrichment presented by the civil scientists in the theory of civil law. The aim of the work is to conduct a comprehensive analysis of the types of obligations resulting from unjust enrichment and substantiate the need for further research on this topic. The methods of scientific knowledge: system, analysis and synthesis. Results: the author's opinion on the proposed topic is expressed and the opinions of other scientists are given. Conclusions: as a result of the study, the author proposed new types of enrichment and presented their characteristics. It allowed revealing loopholes in the civil legislation and developing priority directions which will promote improvement of the norms of this institution.

Key words: unjust enrichment, obligations, classification, advantages of material nature, civil relations, unjust enrichment claim, right to claim.

Citation. Peregudova D.A. Relations Arising from Unjust Enrichment and Their Classification. Legal Concept, 2019, vol. 18, no. 4, pp. 126-130. (in Russian). DOI: https://doi.org/10.15688/lc.jvolsu.2019.4.17

\section{ОТНОШЕНИЯ, ВОЗНИКАЮЩИЕ ВСЛЕДСТВИЕ НЕОСНОВАТЕЛЬНОГО ОБОГАЩЕНИЯ, И ИХ КЛАССИФИКАЦИЯ}

\author{
Дарья Алексеевна Перегудова \\ Волгоградская академия МВД России, г. Волгоград, Российская Федерация
}

\begin{abstract}
Введение: в статье рассматриваются актуальные вопросы, связанные с обязательствами вследствие неосновательного обогащения. В гражданском законодательстве предусмотрена только одна классификация, которая содержит два вида обогащения по способу возникновения: вследствие неосновательного приобретения имущества и вследствие неосновательного сбережения имущества. В связи с этим в статье рассмотрены виды обогащения, представленные учеными-цивилистами в теории гражданского права. Целью работы является проведение комплексного анализа видов обязательств вследствие неосновательного обогащения, а также обоснование необходимости дальнейшего изучения предложенной темы. Методы познания, применяемые для написания работы: анализ и синтез, обобщение, описание и логический метод. Результаты: автором высказано мнение по видам неосновательного обогащения, рассмотрены позиции ученых, предложены решения əे проблем. Выводы: в результате исследования автором предложены новые виды обогащения, представлена их त характеристика. Это позволило выявить пробелы гражданского законодательства и выработать приоритетные направления, которые будут способствовать совершенствованию норм данного институга.

Ключевые слова: неосновательное обогащение, обязательства, классификация, преимущества материального характера, гражданские правоотношения, кондикционный иск, право требования.

Цитирование. Перегудова Д. А. Отношения, возникающие вследствие неосновательного обогащения, и их классификация // Legal Concept = Правовая парадигма. -2019 . - Т. 18, № 4. - C. 126-130. - DOI: https://doi.org/10.15688/lc.jvolsu.2019.4.17
\end{abstract}




\section{Введение}

Обязательства вследствие неосновательного обогащения являются внедоговорными обязательствами, которые предусмотрены Гражданским законодательством Российской Федерации (далее - ГК РФ).

История зарождения института неосновательного обогащения восходит к римскому праву. Впервые положения об обязательствах вследствие неосновательного обогащения были закреплены в ГК РСФСР 1922 года [8].

В настоящее время данный институт является предметом пристального внимания науки гражданского права и относится к комплексным правовым институтам, содержащим элементы частного и публичного права. Однако отсутствие четких законодательных дефиниций, теоретическая неразработанность гражданско-правовых конструкций, а также ряда ключевых правовых категорий, используемых для оценки правоотношений, возникающих вследствие неосновательного обогащения, влечет сложности в применении норм на практике.

\section{Теоретико-правовой анализ видов неосновательного обогащения}

В юридической литературе встречается достаточно много классификаций неосновательного обогащения. Однако нет четкого перечня, который бы наиболее полно отражал признаки и особенности данного института. На сегодняшний день существуют следующие виды неосновательного обогащения:

1. Классификация, следуемая из гражданского законодательства (гл. 60 ГК РФ): приобретение и сбережение имущества за чужой счет; неосновательное обогащение в результате действия потерпевшего и приобретателя; обогащение, возникшее независимо от действий потерпевшего и приобретателя [3]. Обогащение, возникшее в результате действия потерпевшего, характеризуется тем, что потерпевший по ошибке отправил денежные средства или имущество на другой или несуществующий адрес, выполнил работу и не получил ничего взамен и т. п.

Обогащение, возникшее в результате действия приобретателя, - это ситуация, когда лицо незаконно пользуется чужим имуществом, или обогащение в результате противоправных действий. Обогащение, возникшее независимо от действий потерпевшего и приобретателя, это результат действия третьих лиц. Например, выдача груза не должному лицу либо вынос имущества на чужой земельный участок.

2. Классификация, предложенная В.А. Рясенцевым: непосредственное обогащение (лицо неосновательно приобретает или сберегает имущество напрямую, не привлекая третьих лиц) и посредственное обогащение (лицо неосновательно приобретает или сберегает имущество посредством третьего лица). К ситуации посредственного обогащения можно отнести следующий пример: гражданин заказал ремонт автомобиля, принадлежащего ему на праве безвозмездного пользования без разрешения собственника. Собственник автомобиля, узнав об этом, отказался оплачивать ремонт. Следовательно, последний обогатился за счет другого лица, так как автомобиль был отремонтирован, оплата собственником не произведена, а стоимость автомобиля в результате ремонта увеличена [9].

3. Классификация, предложенная ученым-цивилистом А.В. Климовичем: чистое и модифицированное обогащение. Чистое обогащение представляет собой безвозмездную передачу имущества, когда собственник имущества не получает ничего взамен (например, когда вещь украдена и т. д.). Модифицированное обогащение - это неравноценный обмен, когда ценность одного имущества выше или ниже ценности другого имущества. Например, аренда комнаты на условиях значительно ниже стандартных [5].

Классификации, предложенные такими учеными, как В.А. Рясенцев, А.В. Климович, и классификация, указанная в гражданском законодательстве, не могут в полной мере охарактеризовать кондикционные отношения. Взгляд на данный институт как на особый способ защиты прав собственников имущества, а не только как на один из видов обязательств, говорит нам о значимости института неосновательного обогащения в современной России. Обязательства, вызванные обогащением, несомненно связаны нормами нравственности, морали и добросовестности, что требует особого отношения к данному инсти- 
туту и делает его общеюридическим. Это вызывает стремление молодых ученых к его изучению и развитию. Поэтому мнения ученых относительно классификаций данного института, сложившиеся во времена советской науки, требуют переосмысления с учетом современных реалий.

\section{Классификация обязательств в современной науке}

Анализируя представленные выше классификации, мы предлагаем перечень видов обогащения, который позволит охватить весь спектр особенностей данного института: обогащение в узком и широком смысле; обогащение в форме приобретения и сбережения; обогащение вследствие добросовестных и недобросовестных действий приобретателя; обогащение вследствие незаконных действий физических лиц, юридических лиц или публично-правовых образований; обогащение вследствие активного или пассивного поведения приобретателя.

Изучая юридическую литературу, можно заметить, что мнения ученых по поводу классификации неосновательного обогащения в узком и широком смысле расходятся. Так, Д.В. Новак под обогащением в широком смысле понимает несостоявшееся уменьшение имущества как всякое увеличение, то есть когда лицо, обязанное передать часть имущества другому лицу, не передает его. Обогащение в узком смысле - это сохранение имущества одним лицом за счет другого лица [6]. Полагаем, что в данном случае неосновательное обогащение в широком смысле не отличается от неосновательного обогащения в узком смысле. По нашему мнению, результатом сохранения имущества не может быть присоединение новых благ, так как фактического перехода имущества от одного лица к другому лицу не было. В.С. Гербутов оспаривает мнение Д.В. Новак, обосновывая это тем, что сбережение имущества не может возникать в результате присоединения к имуществу лица иной денежной ценности [2]. Д.Д. Гримм считает, что обогащение в узком смысле состоит в том, что одно лицо сберегает или приобретает имущество за счет другого лица. Обогащение в широком смысле заключается в получении приобретателем выгод от использования чужого имущества [4].

Мы считаем, что неосновательное обогащение в узком и широком смысле необходимо понимать следующим образом. Обогащение в узком смысле толкуется как неосновательное приобретение имущества одним лицом за счет другого лица, а обогащение в широком смысле - это применение норм института неосновательного обогащения, когда помимо гражданско-правовых отношений возникают отношения, требующие применения норм публичного права (например, норм уголовного, административного законодательства).

Предложенная нами классификация позволит четко разграничить возникающие между участниками отношения. Например, используя данный институт в широком смысле, применение норм о неосновательном обогащении возможно при расследовании уголовных дел, связанных с незаконным приобретением имущества, при которых нередко обнаруживается большое количество благ, не принадлежащих приобретателю. При совершении неправомерных действий потерпевшие не всегда обращаются в правоохранительные органы для защиты своих прав и восстановления имущественных интересов. Это связано с тем, что собственники не нуждаются в похищенном имуществе или же их личность вовсе не установлена. В связи с этим незаконно приобретенное имущество остается в распоряжении такого приобретателя.

Второй разновидностью является обогащение в форме приобретения и сбережения имущества. Это основные формы неосновательного обогащения в соответствии с ГК РФ. Под приобретением понимают незаконное поступление имущества одного лица к другому лицу, в результате чего имущество у последнего лица увеличивается. М.И. Брагинский и В.В. Витрянский оценивают приобретение чужого имущества обогатившимся как умаление имущественных прав потерпевшего [1]. Сбережение имущества как неосновательное обогащение предполагает, что у обогатившегося лица не происходит уменьшения имущества, так как это лицо не выполняет обязанности по его передаче другому лицу. В словаре Ожегова сбережение трактуется как некая совокупность доходов, не исполь- 
зованная в текущий момент времени [7]. По нашему мнению, данная классификация имеет право на существование лишь исходя из законодательной инициативы. С одной стороны, можно предположить, что формы обогащения позволяют наиболее полно охарактеризовать институт и дифференцировать его от остальных обязательств. С другой стороны, четкое разграничение обогащения на приобретение и сбережение с практической точки зрения не имеет значения. Важен лишь факт обогащения.

Третий вид - обогащение вследствие добросовестных и недобросовестных действий приобретателя. Упоминание об обогащении в большинстве случаев ассоциируется с негативным отношением к обогатившемуся лицу. Предполагается недобросовестность его поведения как участника гражданского правоотношения (удержание ошибочно перечисленных денежных средств, удержание платы за коммунальные услуги). По нашему мнению, само по себе неосновательное обогащение является недобросовестным и незаконным, но оно не всегда может быть вызвано недобросовестными действиями. Например, добросовестные действия будут тогда, когда одному лицу на банковскую карту поступили денежные средства от какогото другого лица, который отправил их ошибочно, то есть перед тем, как одному лицу пришли деньги от другого лица, он действовал добросовестно. Добросовестность и недобросовестность могут проявляться в любом правоотношении, не только в гражданских, - именно в этом, на наш взгляд, проявляется универсализм данного института.

Неосновательное обогамение, возникаютее вследствие незаконных действий физических лии, юридических лич или публично-правовых образований. В соответствии с ГК РФ субъекты именуются как приобретатель и потерпевший. К ним можно отнести широкий круг лиц. Приобретателями и потерпевшими могут быть как малолетние граждане, так и лица недееспособные, как российские граждане, так и иностранные лица, а также публично-правовые образования.

По нашему мнению, необходимость восстановления прав потерпевших может возникнуть в рамках не только гражданского права, но и уголовного и административного права. Это еще раз подтверждает то, что участником такого обязательства может быть абсолютно любое правоспособное лицо, выступающее на равных началах с остальными субъектами. В кондикционном обязательстве не может быть специальных субъектов.

Неосновательное обогащение вследствие пассивного или активного действия (поведения) приобретателя. Пассивное поведение заключается в том, что обогащение возникает помимо воли приобретателя. Лицо не осуществляет никаких действий для того, чтобы обогащение возникло. Например, на Международный женский день сотрудник службы доставки, перепутав необходимый номер квартиры, приносит женщине цветы, которая подразумевает, что это подарок ее мужа. В данном случае женщина не осуществляла никаких специальных действий для того, чтобы приобрести цветы, она относилась к ним, как к своей собственности. При активном поведении приобретатель осуществляет какие-либо незаконные действия, которые влекут неосновательное обогащение. Полагаем, что данная классификация вытекает из существа вышеперечисленных и непременно связана с ними. Например, прямая связь с добросовестными и недобросовестными действиями лица, связь с обогащением, возникшим в результате действий различных субъектов (потерпевшего или приобретателя и т. д.). Резюмируя, можно в очередной раз подчеркнуть универсальный характер института неосновательного обогащения.

\section{Выводы}

В заключение хотелось бы отметить, что теоретико-правовой анализ института неосновательного обогащения показывает, что сформулированные в юридической литературе и гражданском законодательстве виды обогащения не могут в полном объеме раскрыть все многообразие складывающихся между субъектами общественных отношений. Очевидна потребность в их детализации.

Развитие представленного нами в данной работе перечня видов обогащения придаст обязательствам из неосновательного обогащения всеобъемлющий характер и станет 
шагом вперед в развитии российского законодательства.

\section{СПИСОК ЛИТЕРАТУРЫ}

1. Брагинский, М. И. Договорное право : учебник / М. И. Брагинский, В. В. Витрянский. - М. : Статут, 2001. $-638 \mathrm{c}$.

2. Гербутов, В. С. Навязанное обогащение. К учению об обогащении по российскому праву / В. С. Гербутов // Вестник гражданского права. 2011. - Т. 11, № 2. - С. 119-152.

3. Гражданский кодекс Российской Федерации (часть вторая) от 26.01.1996 № 14-Ф3 : (ред. от 18.07.2019). - Электрон. текстовые дан. - Режим доступа: http://www.consultant.ru (дата обращения: 30.08.2019). - Загл. с экрана.

4. Гримм, Д. Д. Очерки по учению об обогащении / Д. Д. Гримм. - СПб. : Тип. Шнакенбурга, $1891 .-107 \mathrm{c}$.

5. Климович, А. В. Кондикционные обязательства в гражданском праве : дис. ... канд. юрид. наук : 12.00.03 / Климович Александр Владимирович. -Иркутск, 2002.-246 с.

6. Новак, Д. В. Неосновательное обогащение в гражданском праве : монография / Д. В. Новак. М. : Статут, 2010. - $416 \mathrm{c}$.

7. Ожегов, С. И. Сбережение // Словарь русского языка Ожегова. - Электрон. текстовые дан. Режим доступа: https://slovar.cc (дата обращения: 30.08.2019). - Загл. с экрана.

8. Пономарева-Пчела, Е. Г. Неосновательное обогащение в Российском гражданском праве / Е. Г. Пономарева-Пчела // Вестник Иркутского государственного технического университета. - 2006. - № 4. - С. 236-239.

9. Рясенцев, В. А. Обязательства из так называемого неосновательного обогащения в советском гражданском праве / В. А. Рясенцев // Ученые записки МГУ. Труды юридического факультета. 1949. - № 144. - C. 85-106.

\section{REFERENCES}

1. Braginsky M.I., Vitryansky V.V. Dogovornoe pravo: uchebnik [Contract Law. Textbook]. Moskow, Statut Publ., 2001. 638 p.

2. Gerbutov V.S. Navyazannoe obogashchenie. $\mathrm{K}$ ucheniyu ob obogashchenii po rossiyskomu pravu [The Imposed Enrichment. To the Doctrine about Enrichment under Russian Law]. Vestnik grazhdanskogo prava, 2011, vol. 11, no. 2, pp. 119-152.

3. Grazhdanskiy kodeks Rossiyskoy Federatsii (chast vtoraya) ot 26.01.1996 № 14-FZ: (red. ot 18.07.2019) [Civil Code of the Russian Federation (Part Two) of January 26, 1996 no. 14-FZ: (Ed. of July 18, 2019)]. URL: http://www.consultant.ru (accessed 30 August 2019).

4. Grimm D.D. Ocherki po ucheniyu ob obogashchenii [Sketches According to the Doctrine about Enrichment]. Saint Petersburg, Tip. Shnakenburga, 1891. 107 p.

5. Klimovich A.V. Kondiktsionnye obyazatelstva v grazhdanskom prave: dis. ... kand. yurid. nauk: 12.00.03 [Kondiktsionnye of the Obligation in Civil Law. Cand. jurid. sci. diss.]. Irkutsk, 2002. 246 p.

6. Novak D.V. Neosnovatelnoe obogashchenie v grazhdanskom prave: monografiya [Unjust Enrichment in Civil Law. Monograph]. Moskow, Statut Publ., 2010. 416 p.

7. Ozhegov S.I. Sberezhenie [Saving]. Slovar russkogo yazyka Ozhegova [Dictionary Ozhegova]. URL: https://slovar.cc (accessed 30 August 2019).

8. Ponomareva-Pchela E.G. Neosnovatelnoe obogashchenie $\mathrm{v}$ Rossiyskom grazhdanskom prave [Unjust Enrichment in the Russian Civil Law]. Vestnik Irkutskogo gosudarstvennogo tekhnicheskogo universiteta, 2006, no. 4, pp. 236-239.

9. Ryasentsev V.A. Obyazatelstva iz tak nazyvaemogo neosnovatelnogo obogashcheniya $\mathrm{V}$ sovetskom grazhdanskom prave [Obligations from Socalled Unjust Enrichment in the Soviet Civil Law]. Uchenye zapiski MGU. Trudy yuridicheskogo fakulteta, 1949, no. 144, pp. 85-106.

\section{Information about the Author}

Daria A. Peregudova, Senior Police Lieutenant, Junior Scientific Assistant, Department of Civil Law, Volgograd Academy of the Ministry of Internal Affairs of the Russian Federation, Istoricheskaya St., 130, 400089 Volgograd, Russian Federation, dashaperegudova7@yandex.ru, https://orcid.org/0000-0003-4700-065X

\section{Информация об авторе}

Дарья Алексеевна Перегудова, старший лейтенант полиции, адъюнкт кафедры гражданского права, Волгоградская академия МВД России, ул. Историческая, 130, 400089 г. Волгоград, Российская Федерация, dashaperegudova7@yandex.ru, https://orcid.org/0000-0003-4700-065X 